\title{
Avaliação do impacto de um suplemento nutricional rico em ferro hematínico
}

\author{
Evaluating the impact of a hematinic \\ iron-rich nutritional supplement
}

Miriam Correa de Carvalho Simões 1

Erly Catarina Moura 2

Valdemiro Carlos Sgarbieri 1

Dalcélia Bueno de Figueiredo ${ }^{3}$

\footnotetext{
${ }^{1}$ Departamento de Planejamento Alimentar e Nutrição, Faculdade de Engenharia de Alimentos, Universidade Estadual de Campinas. Cidade Universitária Zeferino Vaz, Barão Geraldo, Campinas, SP 13083-970, Brasil.

2 Departamento de Nutrição, Faculdade de Ciências Médicas, Pontifícia Universidade Católica de Campinas. Av. John Boyd Dunlop s/no, Campinas, $S P$ 13059-740, Brasil.

lymoura@aleph.com.br

3 Laboratório de Análises Clínicas, Hospital

Maternidade Celso Pierro, Pontifícia Universidade Católica de Campinas. Av. John Boyd Dunlop s/no, Campinas, $S P$, 13059-740, Brasil.
}

\begin{abstract}
A quasi-experimental epidemiological study was performed to evaluate the effect of a nutritional supplement made from bovine blood on human blood parameters. Healthy women who were neither pregnant nor breast-feeding were allocated to two groups: study $(n=32)$ and control $(n=17)$. Women in the study group received $0.5 \mathrm{mg}$ of iron per day, while controls received placebo. Food intake frequency and side effects related to ferrous sulfate were recorded. A 24-hour dietary recall was performed every two weeks, and blood samples were collected to determine biochemical parameters. Compared to controls, the study group showed higher serum iron and iron retention capacity, lower calorie, protein, and vitamin C intake, and lower consumption of dairy products and fruit. Adjusted mean blood parameters were calculated using ANOVA. The output showed increased serum iron $(p=0.009)$ and decreased iron retention capacity ( $p=0.031$ ) at the end of the study. The results favor use of the product to treat iron deficiency anemia.
\end{abstract}

Key words Iron-deficiency Anemia; Suplementary Feeding; Hemoglobins; Iron; Nutrition

Resumo Estudo quase-experimental foi desenvolvido junto a 49 mulheres sadias para se avaliar o impacto de um produto do sangue bovino nos níveis hematológicos. Ao grupo experimental $(n=32)$ prescreveu-se $0,5 \mathrm{mg}$ de ferro ao dia e ao controle $(n=17)$, placebo. Freqüência de consumo de alimentos e sintomas associados ao sulfato ferroso foram registrados. Inquérito alimentar foi realizado a cada 15 dias, assim como coleta de sangue para dosagem bioquímica. Observou-se maior diferença para o ferro sérico, no grupo experimental, e menor de capacidade latente de fixação de ferro nas segunda, terceira e quinta coletas. Quanto à dieta, verificou-se para o grupo experimental menor ingestão de calorias, proteínas e vitamina $C$ na quinta coleta e menor consumo de leite e derivados nas terceira, quarta e quinta coletas e de frutas na quarta coleta. Após a incorporação destas variáveis, para o cálculo das médias ajustadas, encontrou-se diferença significativamente maior para o ferro sérico $(p=0,009)$ e menor para a CLFF $(p=0,031)$ ao final do estudo. Os resultados indicam a viabilidade do uso deste produto na deficiência de ferro. Palavras-chave Anemia Ferropriva; Suplementação Alimentar; Hemoglobinas; Ferro; Nutrição 


\section{Introdução}

A anemia por deficiência de ferro é isoladamente a mais comum das deficiências nutricionais do mundo e ocorre como resultado de perda sangüínea crônica, perdas urinárias, ingestão e/ou absorção deficiente e aumento do volume sangüíneo. Estimativas recentes situam em, pelo menos, um bilhão o número de pessoas portadoras dessa deficiência em todo o mundo, e os lactentes, as crianças e as mulheres representam os grupos mais vulneráveis (Batista-Filho \& Ferreira, 1996; Freire, 1998; Walker, 1998).

A deficiência de ferro ocorre quando a quantidade de ferro total do organismo está diminuída. Três estágios podem ser identificados (Hallberg et al., 1993), cada um mudando gradativamente para o outro, de acordo com a gravidade da deficiência. O primeiro estágio se caracteriza pela queda da ferritina sérica. No segundo estágio, a saturação da transferrina está diminuída. O terceiro estágio se caracteriza pela redução da hemoglobina, microcitose e hipocromia.

Esta situação tem levado ao desenvolvimento de suplementos nutricionais para o tratamento da anemia ferropriva. No Brasil, o sulfato ferroso é a fonte de ferro mais utilizada para a suplementação; entretanto, por ser um ferro inorgânico, não hematínico, sua absorção pode ser comprometida por inúmeros fatores, além da presença de efeitos colaterais (Simmons et al., 1993; Galloway \& McGuire, 1994). Por outro lado, o ferro hematínico, proveniente da hemoglobina e da mioglobina (presentes no sangue e músculo, respectivamente), apresenta uma taxa de absorção muito maior que o ferro não hematínico, constituindo-se, assim, em uma excelente fonte de ferro para a utilização como suplemento nutricional (Walter et al., 1993; Walker, 1998).

O sangue bovino, um subproduto de abatedouros, tem sido objeto de numerosos estudos nos últimos anos (Lee et al.,1987; Domene, 1988; Cheftel, 1989; Nogueira et al., 1992) por ser uma fonte não tradicional de nutrientes, assim como uma excelente fonte de ferro hematínico, de relativo baixo custo, com propriedades organolépticas e funcionais adequadas ao consumo humano. A quantidade de sangue disponível nos abatedouros é grande, visto que o volume coletado por animal, com faca de sangria, representa cerca de $3,5 \%$ do seu peso vivo ou $50 \%$ do volume total de sangue circulante, sendo este obtido no tempo estimado de sessenta segundos. Modernas instalações de abate permitem, por bovino, uma coleta média de
10 a 12 litros de sangue, que contém $17 \%$ de proteína. Destes $17 \%, 11 \%$ se concentram na hemoglobina. O sangue bovino, quando tratado com anticoagulante e separado através de centrifugação, apresenta 35\% a $40 \%$ de concentrado de hemácias ou fração celular.

A utilização do sangue bovino como fonte de ferro para seres humanos pode ser de grande interesse, pois a deficiência de ferro se faz presente em todos os estratos da população, e a busca de alternativas para a melhoria deste problema de saúde pública é de fundamental importância. Neste sentido, foi desenvolvido um produto, proveniente da fração celular sangüínea desidratada de bovinos, rico em ferro hematínico, para uso humano. Este trabalho tem como objetivo avaliar o impacto deste produto nos níveis hematológicos de seres humanos.

\section{Metodologia}

Este estudo foi realizado na Faculdade de Ciências Médicas da Pontifícia Universidade Católica de Campinas (PUC-Campinas), após aprovação pelo Comitê de Ética em Pesquisa (por se tratar de pesquisa de risco mínimo envolvendo seres humanos), ensaio biológico em ratos e análise microbiológica (Simões, 1998). A observação de princípios éticos conforme as normas e diretrizes regulamentadoras de pesquisas envolvendo seres humanos (FNS, 1996) implicou, ainda, a responsabilidade de se evitar os danos previsíveis decorrentes ou não da pesquisa, providenciando assistência médica integral aos participantes, o que foi garantido pelos médicos assistenciais da PUC-Campinas, locados no Centro de Saúde Escola do Jardim Campos Elíseos. A divulgação do trabalho foi realizada por meio de cartazes colocados em pontos estratégicos e palestras aos alunos e funcionários desta faculdade. As pessoas interessadas em participar do estudo, como voluntárias, receberam uma carta de consentimento, explicativa do estudo, que nos autorizava, após assinatura, a incluí-las na pesquisa. Cada participante preencheu uma ficha de inscrição com dados de identificação, posteriormente completada com dados antropométricos.

\section{Tipo de estudo}

O tipo de estudo utilizado para determinar o impacto da suplementação em seres humanos foi o estudo epidemiológico quase-experimental. O estudo quase-experimental caracterizase por ser um estudo de campo, no qual dois 
grupos são estudados, ou seja, um grupo (experimental) recebe a intervenção que se quer estudar e o outro grupo (controle) não recebe a intervenção, recebendo, porém, um placebo (no caso de medicamentos). Estes dois grupos são, então, comparados entre si, e verifica-se a eficácia do tratamento. Neste tipo de estudo, o observador tem o controle da escolha dos indivíduos e dos grupos de estudo. Este tipo de estudo permite que cada sujeito, acompanhado em diferentes momentos, seja seu próprio controle, através das observações das respostas variáveis, antes e depois da intervenção, possibilitando também testar a eficácia ou o resultado da intervenção no grupo (Kleinbaum et al., 1982).

\section{População de estudo}

O estudo foi realizado com a formação de dois grupos: um experimental e um de controle. $\mathrm{O}$ critério de ingresso exigia a normalidade dos índices hematimétricos, isto é, eliminava qualquer possibilidade de anemia ferropriva, por se tratar de primeira fase de investigação em seres humanos. Os sujeitos do estudo foram mulheres adultas sadias, entre 18 e 44 anos, não grávidas nem lactantes, voluntárias, pareadas de acordo com a idade e o índice de massa corporal (IMC). Procurou-se selecionar para cada dois casos (grupo experimental) um controle na mesma faixa etária (18 a 19,9; 20 a 24,9; 25 a 29,9; 30 a 39,9; e 40 a 49,9 anos) e faixa de IMC (18 a 19,$9 ; 20$ a 24,$9 ; 25$ a 29,9 ; e 30 a 34,9 $\mathrm{kg} / \mathrm{m}^{2}$ ). O estudo contou com a participação de 49 voluntárias, sendo o grupo experimental composto por 32 mulheres e o de controle por 17. O estudo durou sessenta dias, e as determinações hematimétricas foram realizadas quinzenalmente. Ao grupo experimental foi prescrito $0,5 \mathrm{mg}$ de ferro ao dia (biodisponibilidade de ferro de $20 \%$, conforme Stekel et al., 1986), durante o período do estudo, com base nas perdas que as mulheres em idade fértil sofrem com a menstruação (Carpenter \& Mahoney, 1992), e ao grupo controle, placebo contendo amido. À cada pessoa foi indicada a ingestão de três cápsulas ao dia, após as refeições principais (desjejum, almoço e jantar). Todas as pessoas receberam dois frascos contendo cápsulas suficientes para todo o experimento. Tanto as cápsulas quanto os rótulos dos frascos dos dois grupos foram idênticos, para que os sujeitos do estudo não soubessem a que grupo pertenciam. A fração celular desidratada foi encapsulada na sua forma natural pela Farmácia de Manipulação Fórmula e Cia. As cápsulas foram produzidas todas de uma só vez, conservadas à temperatura ambiente, devidamente protegidas de umidade, e distribuídas aos grupos no início do experimento. Ao final do experimento, os participantes receberam uma carta de agradecimento pela participação na pesquisa e os resultados das análises hematológicas realizadas.

\section{Variáveis estudadas}

Idade, peso e altura foram determinadas no início do experimento. O peso foi determinado utilizando-se balança eletrônica digital (marca Sreight). Os indivíduos foram pesados com roupas leves, em jejum, no início do dia. A altura foi medida por antropômetro vertical (marca Stanley). O peso e altura foram utilizados no cálculo do IMC, ou Índice de Quetelet, utilizando-se a equação do peso dividido pelo quadrado da altura (Vasconcelos, 1995). Inquérito alimentar recordatório de 24 horas (Willett, 1998) foi realizado quinzenalmente, para a caracterização da dieta dos participantes. Os alimentos ingeridos na véspera do dia da coleta, registrados em medidas caseiras, foram transformados em peso para o cálculo dietético. Utilizou-se o programa AVANU (Tabacniks \& Moura, 1992) para o cálculo de calorias, carboidratos, proteína, lipídios, ferro e vitamina C. Além disso, todos os alimentos consumidos durante o período do estudo foram registrados pelos próprios participantes (orientados logo no início e durante o estudo) em instrumento próprio (Krebs-Smith \& Clark, 1989). Os alimentos foram, então, classificados de acordo com os subgrupos de alimentos: leite e derivados; carnes; legumes e verduras; frutas; e alimentos energéticos (cereais, feculentos e derivados). Sintomas normalmente relacionados à ingestão de sulfato ferroso, como diarréia, náusea, vômito, alterações do hábito intestinal, dor abdominal e cefaléia, foram também investigados (Simmons et al., 1993; Galloway \& McGuire, 1994).

Foram consideradas como dependentes, as variáveis hematimétricas. As coletas de sangue foram realizadas por uma enfermeira e duas técnicas de enfermagem do Centro de Saúde Escola do Jardim Campos Elíseos. Cerca de 15 $\mathrm{ml}$ de sangue foram colhidos por punção venosa, pelo sistema vacuttainer, em três frascos secos, para as dosagens de ferro sérico, capacidade latente de fixação de ferro (CLFF) e ferritina, e em um frasco contendo anticoagulante EDTA a $10 \%$, para a dosagem de hemoglobina, hematócrito, volume corpuscular médio (VCM) e eletroforese de hemoglobina. As amostras de sangue foram processadas num prazo máximo 
de cinco horas no Laboratório de Análises Clínicas do Hospital e Maternidade Celso Pierro da PUC-Campinas em equipamentos automatizados. O ferro sérico foi determinado pelo método colorimétrico com ferrozine e ácido ascórbico (Williams et al., 1977) e a CLFF foi determinada pelo método de determinação direta com ferrozine (Bauer et al., 1962). A ferritina sérica foi determinada por imuno ensaio enzimático - ELISA (Tietz, 1987). A eletroforese de hemoglobina foi realizada em gel de agarose corrida em cuba eletroforética e lida em densitômetro DS-35 da CELM (Naoum, 1987). O eritrograma (hemoglobina, hematócrito e volume corpuscular médio-VCM) foi determinado por resistividade elétrica e impedância (Davidsohn \& Henry, 1974).

\section{Formulação de hipóteses}

A fração celular desidratada tem sido utilizada em alguns estudos de fortificação de alimentos, sendo que alterações gastrointestinais não foram presenciadas (Asenjo et al., 1985; Stekel et al., 1986; Walter et al., 1993). Isto se explica pelo fato de que o ferro presente nesta fração (ferro hematínico) apresenta um metabolismo de absorção totalmente independente da dieta, sendo absorvido intacto pela mucosa intestinal, não causando desconforto decorrente de sua digestão e/ou absorção, ao contrário dos sais de ferro (ferro não hematínico), geralmente utilizados no mercado de suplementação, cuja principal característica são os efeitos colaterais, além das interferências absortivas decorrentes da composição da dieta. Baseados nesses fatos, não era esperado efeito colateral.

Quanto aos níveis hematimétricos, decidiuse estudar alguns parâmetros sangüíneos que poderiam representar melhor os resultados obtidos com a ingestão deste suplemento. O estudo com pessoas sadias torna difícil diferenciar alguma alteração do nível de hemoglobina, pois todos os participantes do estudo apresentavam níveis satisfatórios de hemoglobina no início do experimento. Assim, o nível de ferro sérico foi considerado como indicador da resposta imediata à absorção do ferro suplementar, que deveria aumentar no grupo experimental, logo no início do estudo. Segundo Williams et al. (1977), o ferro sérico é o método indicado para diagnosticar deficiências de ferro, repleção e, também, sobrecarga de ferro no organismo. A CLFF, que representa a transferrina livre ou não saturada, disponível para a ligação com o ferro sérico para o transporte deste, tenderia a diminuir no grupo experimental, pois, uma vez aumentada a quantidade de ferro sérico, menos transferrina livre estaria disponível. Nos casos de anemia, pode-se encontrar níveis alterados, ou seja, uma quantidade diminuída de ferro sérico em contraste com os níveis elevados de CLFF (Bauer et al., 1962; Rapaport, 1990). A ferritina sérica, que corresponde aos estoques de ferro do organismo, foi também determinada. A diminuição dos seus níveis plasmáticos no desenvolvimento da deficiência de ferro ocorre precocemente. A diminuição dos estoques de ferro inicia-se com a diminuição da ferritina intracelular e conseqüente diminuição da ferritina extracelular. A determinação dos níveis de ferritina extracelular pode ser efetuada diretamente pela dosagem de ferritina sérica presente no plasma (Tietz, 1987; Henry, 1995). A opção de determinar o nível de ferritina sérica neste estudo foi baseada no fato de que aumentando a quantidade de ferro biodisponível, no grupo experimental, os estoques de ferro poderiam também aumentar. Segundo Rapaport (1990), os níveis de ferro sérico, CLFF e ferritina, quando alterados, correspondem, juntos, ao primeiro estágio de depleção de ferro. Desta forma, a observação desses parâmetros é importante para verificar as modificações ocorridas nos dois grupos.

Ainda segundo Rapaport (1990), o volume corpuscular médio é o mais importante dos índices hematimétricos, pois mostra o tamanho da hemácia, sendo de grande importância para o diagnóstico de anemia. O VCM é calculado dividindo-se o número de hematócrito pelo número de hemácias (Gorina \& Jiménez, 1974). Valores baixos significam microcitose e valores altos macrocitose (Davidson \& Henry, 1974). Neste sentido, os valores de VCM foram também determinados, assim como os de hematócrito. Os hematócritos representam o volume dos eritrócitos no sangue circulante, valores abaixo de $35 \%$ podem indicar anemia (Gorina \& Jiménez, 1974).

O último estágio da deficiência de ferro, ou anemia, é caracterizado pela diminuição da concentração de hemoglobina. Esta proteína, principal componente das células vermelhas, é responsável pelo transporte do oxigênio e do dióxido de carbono. A concentração nas mulheres pode oscilar entre $11,5 \mathrm{~g} / \mathrm{dl}$ a $16,4 \mathrm{~g} / \mathrm{dl}$ (Gorina \& Jiménez, 1974). A eletroforese de hemoglobina (Naoum, 1987) foi realizada para verificar se os participantes do estudo apresentavam níveis e estruturas de hemoglobina normais.

Optou-se pelo estudo dos principais parâmetros hematológicos relacionados aos está- 
gios da deficiência de ferro, supondo-se que apresentariam níveis normais ou alterados pelo excesso de ferro no grupo experimental contrariamente ao grupo placebo.

\section{Análise estatística}

Para as variáveis quantitativas contínuas, foram calculadas a média e o desvio padrão utilizados na comparação entre os dois grupos estudados pelo teste 't' de Student. As variáveis independentes (dietéticas) que se mostraram estatisticamente diferentes entre os dois grupos foram incorporadas enquanto co-variáveis para o cálculo das médias ajustadas das variáveis dependentes (hematimétricas), no modelo fatorial ANOVA (SPSS, 1992), a fim de controlar a influência da dieta no resultado final. Considerou-se intervalo de confiança de $95 \%$ e nível de significância de 5\% (p0,05).

\section{Resultados e discussão}

\section{Caracterização da população ao início do estudo}

Participaram do estudo 49 mulheres, com idade mínima de 18 anos e máxima de 44, divididas em dois grupos, pareados conforme idade e IMC, de modo a não apresentar diferença sig- nificante quanto a estas variáveis. Pode-se observar que os dois grupos se apresentaram homogêneos quanto às características hematimétricas, com exceção do índice de ferro sérico, que foi menor no grupo caso. As características dietéticas, avaliadas pela ingestão média diária de calorias, carboidratos, lipídios, proteínas, ferro e vitamina $C$, também apresentaram-se semelhantes para os dois grupos estudados (Tabela 1).

\section{Variações hematimétricas durante o estudo}

A análise dos resultados hematimétricos apresentados durante o estudo do impacto da suplementação de ferro no grupo experimental em relação ao grupo controle foi realizada, considerando-se as diferenças apresentadas em cada coleta em relação à primeira coleta. A Tabela 2 mostra os resultados das médias das diferenças hematimétricas para os dois grupos. Pode-se observar que, do total de 49 participantes que iniciaram o estudo, quatro desistiram no decorrer do mesmo, sendo três do grupo experimental e uma do grupo controle. Na terceira coleta houve a exclusão de duas pessoas do grupo experimental, uma com suspeita de apendicite e outra com problemas gastrointestinais não relacionados ao consumo deste suplemento. Na quarta coleta, uma pessoa do grupo experimental saiu do estudo por ter difi-

Tabela 1

Características físicas, hematimétricas e dietéticas da população (total, experimental e controle) no início do estudo. Campinas, 1997.

\begin{tabular}{|c|c|c|c|c|}
\hline Características da população & $\begin{array}{c}\text { Total } \\
(n=49)\end{array}$ & $\begin{array}{c}\text { Experimental } \\
(n=32)\end{array}$ & $\begin{array}{c}\text { Controle } \\
(n=17)\end{array}$ & $\mathrm{p}$ \\
\hline Idade (anos) & $22,1 \pm 5,1$ & $22,3 \pm 5,8$ & $21,9 \pm 3,6$ & 0,80 \\
\hline $\mathrm{IMC}\left(\mathrm{Kg} / \mathrm{m}^{2}\right)$ & $21,7 \pm 2,7$ & $21,9 \pm 2,8$ & $21,1 \pm 2,3$ & 0,32 \\
\hline Peso $(\mathrm{Kg})$ & $56,6 \pm 7,5$ & $57,9 \pm 7,9$ & $54,2 \pm 6,3$ & 0,10 \\
\hline Altura $(\mathrm{cm})$ & $161,7 \pm 5,8$ & $162,5 \pm 5,4$ & $160,2 \pm 6,3$ & 0,19 \\
\hline Ferro Sérico $(\mu \mathrm{g} / \mathrm{dl})$ & $62,4 \pm 29,1$ & $54,9 \pm 26,9$ & $76,4 \pm 28,4$ & 0,01 \\
\hline $\operatorname{CLFF}(\mu \mathrm{g} / \mathrm{dl})$ & $234,8 \pm 64,9$ & $248,1 \pm 62,9$ & $209,7 \pm 63,0$ & 0,05 \\
\hline Ferritina sérica (ng/dl) & $40,0 \pm 24,7$ & $44,6 \pm 27,7$ & $31,5 \pm 15,1$ & 0,08 \\
\hline Hemoglobina ( $\mathrm{g} \%$ ) & $13,0 \pm 0,8$ & $12,9 \pm 0,7$ & $13,1 \pm 0,8$ & 0,42 \\
\hline Hematócrito (ml) & $38,1 \pm 2,1$ & $37,8 \pm 2,0$ & $38,6 \pm 2,2$ & 0,21 \\
\hline VCM (fL) & $84,7 \pm 4,4$ & $84,5 \pm 3,7$ & $84,9 \pm 5,8$ & 0,76 \\
\hline Energia (Kcal) & $1893 \pm 514$ & $1873 \pm 504$ & $1931 \pm 544$ & 0,71 \\
\hline Carboidratos (g) & $231,1 \pm 75,1$ & $233,3 \pm 77,9$ & $227,1 \pm 71,9$ & 0,79 \\
\hline Lipídeos (g) & $80,5 \pm 25,3$ & $79,2 \pm 22,2$ & $82,9 \pm 31,0$ & 0,63 \\
\hline Proteína (g) & $62,9 \pm 23,5$ & $59,02 \pm 22,2$ & $70,2 \pm 24,8$ & 0,11 \\
\hline Ferro (mg) & $10,8 \pm 4,1$ & $10,6 \pm 4,4$ & $11,3 \pm 3,5$ & 0,54 \\
\hline Vitamina $C(\mathrm{mg})$ & $101,5 \pm 87,7$ & $91,3 \pm 84,2$ & $120,9 \pm 93,3$ & 0,26 \\
\hline
\end{tabular}


culdade em ingerir as cápsulas e outra do grupo controle, por iniciar medicação para perda de peso. Observa-se, também, que apenas uma participante do grupo controle não compareceu à quarta coleta. Todos as participantes do estudo apresentaram níveis e estrutura de hemoglobina normais.

Encontrou-se diferença significante quanto ao ferro sérico e CLFF nas segunda, terceira e quinta coletas, sendo que, em todas elas, a diferença do ferro sérico em relação ao início do estudo foram maiores para o grupo experimental do que para o controle, isto é, o ferro sérico aumentou mais no grupo experimental, ocorrendo o inverso com a CLFF. Esta inversão era de se esperar, conforme relata Williams et al. (1977), pois o grupo experimental recebeu uma quantidade de ferro biodisponível bem maior do que o grupo controle. A ferritina sérica, na terceira coleta, diminuiu mais no grupo experimental do que no controle e o VCM, na quarta coleta, mostrou-se mais reduzido no grupo controle do que no grupo caso; a ferritina apresentou uma tendência ao declínio dos seus níveis na terceira e quarta coletas nos dois grupos, entretanto seus valores, tanto para o grupo experimental como para o grupo controle, permaneceram dentro dos limites normais de referência (Tietz, 1987). A amplitude dos valores dos índices hematimétricos ocasionou um alto desvio padrão nos dois grupos estudados, diferença incorporada na análise dos resultados, ao se optar pelo cálculo ajustado das médias.

Variações hematimétricas durante o estudo. Campinas, 1977.

\begin{tabular}{|c|c|c|c|c|}
\hline Variações & Total & Experimental & Controle & $\mathrm{p}$ \\
\hline 2a coleta & $(n=49)$ & $(n=32)$ & $(n=17)$ & \\
\hline Ferro Sérico $(\mu \mathrm{g} / \mathrm{dl})$ & $17,9 \pm 39,2$ & $29,6 \pm 37,6$ & $-3,4 \pm 33,4$ & 0,004 \\
\hline C.L.F.F. $(\mu g / d l)$ & $24,9 \pm 49,6$ & $11,6 \pm 44,2$ & $49,9 \pm 44,2$ & 0,009 \\
\hline Ferritina sérica (ng/dl) & $1,4 \pm 11,9$ & $0,5 \pm 12,6$ & $3,0 \pm 10,7$ & 0,487 \\
\hline Hemoglobina (g\%) & $0,04 \pm 0,5$ & $0,05 \pm 0,5$ & $0,02 \pm 0,5$ & 0,862 \\
\hline Hematócrito (ml \%) & $1,08 \pm 1,6$ & $1,21 \pm 1,5$ & $0,85 \pm 1,9$ & 0,474 \\
\hline $\operatorname{VCM}(f \mathrm{~L})$ & $0,27 \pm 0,9$ & $0,28 \pm 0,9$ & $0,24 \pm 0,8$ & 0,861 \\
\hline 3ạ coleta & $(n=47)$ & $(n=30)$ & $(n=17)$ & \\
\hline Ferro Sérico ( $\mu \mathrm{g} / \mathrm{dl})$ & $15,7 \pm 37,1$ & $23,7 \pm 36,9$ & $1,6 \pm 34,0$ & 0,048 \\
\hline C.L.F.F. $(\mu \mathrm{g} / \mathrm{dl})$ & $73,7 \pm 48,2$ & $61,1 \pm 45,5$ & $95,9 \pm 46,0$ & 0,015 \\
\hline Ferritina sérica (ng/dl) & $-3,9 \pm 9,4$ & $-6,0 \pm 8,9$ & $-0,22 \pm 9,4$ & 0,043 \\
\hline Hemoglobina (g\%) & $0,01 \pm 0,5$ & $0,0 \pm 0,4$ & $0,02 \pm 0,6$ & 0,880 \\
\hline Hematócrito (ml \%) & $0,46 \pm 1,8$ & $0,57 \pm 1,6$ & $0,26 \pm 2,2$ & 0,583 \\
\hline $\operatorname{VCM}(f L)$ & $2,5 \pm 2,7$ & $2,5 \pm 3,3$ & $2,5 \pm 1,2$ & 0,941 \\
\hline 4a coleta & $(n=44)$ & $(n=9)$ & $(n=15)$ & \\
\hline Ferro Sérico $(\mu \mathrm{g} / \mathrm{dl})$ & $31,2 \pm 36,8$ & $35,8 \pm 33,6$ & $22,3 \pm 42,0$ & 0,252 \\
\hline C.L.F.F. $(\mu \mathrm{g} / \mathrm{dl})$ & $52,2 \pm 68,0$ & $48,0 \pm 63,4$ & $60,5 \pm 77,9$ & 0,569 \\
\hline Ferritina sérica (ng/dl) & $-13,4 \pm 13,6$ & $-14,4 \pm 14,5$ & $-11,6 \pm 11,9$ & 0,522 \\
\hline Hemoglobina (g\%) & $-0,12 \pm 0,6$ & $-0,06 \pm 0,6$ & $-0,24 \pm 0,7$ & 0,352 \\
\hline Hematócrito (ml \%) & $-1,61 \pm 2,1$ & $-1,28 \pm 1,8$ & $-2,24 \pm 2,4$ & 0,144 \\
\hline $\operatorname{VCM}(f L)$ & $-2,5 \pm 1,3$ & $-2,2 \pm 1,0$ & $-3,1 \pm 1,6$ & 0,042 \\
\hline 5a coleta & $(n=45)$ & $(n=29)$ & $(n=16)$ & \\
\hline Ferro Sérico $(\mu \mathrm{g} / \mathrm{dl})$ & $26,3 \pm 40,8$ & $35,2 \pm 39,2$ & $10,1 \pm 39,7$ & 0,047 \\
\hline C.L.F.F. $(\mu \mathrm{g} / \mathrm{dl})$ & $8,2 \pm 56,1$ & $-6,1 \pm 46,3$ & $34,3 \pm 63,9$ & 0,019 \\
\hline Ferritina sérica (ng/dl) & $-0,8 \pm 14,6$ & $-1,7 \pm 15,5$ & $0,7 \pm 13,2$ & 0,604 \\
\hline Hemoglobina (g\%) & $-0,06 \pm 0,5$ & $0,01 \pm 0,5$ & $-0,19 \pm 0,7$ & 0,236 \\
\hline Hematócrito (ml \%) & $0,52 \pm 1,8$ & $0,82 \pm 1,6$ & $-0,03 \pm 2,0$ & 0,130 \\
\hline VCM (fL) & $2,9 \pm 1,1$ & $3,0 \pm 1,2$ & $2,6 \pm 1,0$ & 0,276 \\
\hline
\end{tabular}




\section{Características dietéticas durante o estudo}

Após cada coleta de sangue, foi realizado o recordatório alimentar de 24 horas para a caracterização dietética dos macronutrientes (glicídios, lipídios e proteínas), energia, além do ferro e vitamina $\mathrm{C}$, com a finalidade de controlar a interferência da dieta nos níveis hematimétricos. A freqüência alimentar, também utilizada para este controle, foi calculada, dividindose o número de vezes dos alimentos de cada grupo presente na dieta pelo número de dias do período, em cinco subgrupos (leite e derivados; carnes; legumes e verduras; frutas; e alimentos energéticos). A Tabela 3 apresenta os resultados do recordatório, e a Tabela 4 , os resultados da freqüência alimentar. Observou-se na quinta coleta, maior teor de calorias, proteínas e vitamina $\mathrm{C}$ no grupo controle do que no experimental, bem como maior ingestão de leite e derivados, na terceira, quarta e quinta coletas, e de frutas na quarta coleta.

\section{Sinais e sintomas durante o estudo}

Os sinais e sintomas apresentados durante o estudo foram medidos, dividindo-se a ocorrência destes apresentada no período entre cada coleta de sangue pelo número de dias do período. Não se observou diferença estatística significante para os sinais e sintomas apresentados entre os dois grupos durante o estudo. Para a quarta coleta, que apresentou o menor valor de p $(0,05)$, embora não estatisticamente diferen-

Características dietéticas (recordatório de 24 h) durante o estudo. Campinas, 1997.

\begin{tabular}{|c|c|c|c|c|}
\hline Caracterîsticas & Total & Experimental & Controle & $p$ \\
\hline 2a coleta & $(n=49)$ & $(n=32)$ & $(n=17)$ & \\
\hline Energia (Kcal) & $1939 \pm 739$ & $1884 \pm 752$ & $2043 \pm 725$ & 0,48 \\
\hline Glicídios (g) & $227,9 \pm 114,1$ & $214,2 \pm 100,8$ & $253,8 \pm 135,4$ & 0,25 \\
\hline Lipídios (g) & $81,9 \pm 30,2$ & $82,3 \pm 33,2$ & $81,0 \pm 24,5$ & 0,89 \\
\hline Proteína (g) & $72,9 \pm 28,2$ & $71,9 \pm 30,1$ & $75,0 \pm 25,0$ & 0,72 \\
\hline Ferro (mg) & $12,4 \pm 5,5$ & $11,8 \pm 5,7$ & $13,5 \pm 4,9$ & 0,31 \\
\hline Vitamina C (mg) & $115,4 \pm 121,1$ & $110,2 \pm 128,0$ & $125,0 \pm 109,9$ & 0,69 \\
\hline 3a coleta & $(n=47)$ & $(n=30)$ & $(n=17)$ & \\
\hline Energia (Kcal) & $1795 \pm 485$ & $1769 \pm 493$ & $1839 \pm 483$ & 0,65 \\
\hline Glicídios (g) & $215,2 \pm 83,0$ & $203,4 \pm 78,1$ & $235,4 \pm 89,4$ & 0,21 \\
\hline Lipídios (g) & $72,6 \pm 19,6$ & $74,4 \pm 20,2$ & $69,5 \pm 19,1$ & 0,42 \\
\hline Proteína (g) & $70,5 \pm 33,7$ & $71,8 \pm 39,3$ & $68,3 \pm 22,3$ & 0,74 \\
\hline Ferro (mg) & $11,1 \pm 4,6$ & $10,4 \pm 4,1$ & $12,5 \pm 5,1$ & 0,14 \\
\hline Vitamina C (mg) & $136,0 \pm 114,7$ & $123,6 \pm 106,2$ & $157,3 \pm 128,5$ & 0,34 \\
\hline 4a coleta & $(n=44)$ & $(n=29)$ & $(n=15)$ & \\
\hline Energia (Kcal) & $1942 \pm 671$ & $1895 \pm 692$ & $2030 \pm 644$ & 0,54 \\
\hline Glicídios (g) & $217,2 \pm 99,1$ & $207,1 \pm 100,9$ & $235,9 \pm 96,2$ & 0,37 \\
\hline Lipídios (g) & $84,2 \pm 32,0$ & $82,8 \pm 32,3$ & $86,8 \pm 32,3$ & 0,70 \\
\hline Proteína (g) & $79,0 \pm 31,1$ & $80,5 \pm 35,0$ & $76,3 \pm 23,1$ & 0,68 \\
\hline Ferro (mg) & $10,7 \pm 4,2$ & $10,4 \pm 4,0$ & $11,2 \pm 4,5$ & 0,51 \\
\hline Vitamina C (mg) & $129,9 \pm 106,6$ & $122,2 \pm 88,4$ & $144,2 \pm 136,8$ & 0,53 \\
\hline 5a coleta & $(n=45)$ & $(n=29)$ & $(n=16)$ & \\
\hline Energia (Kcal) & $1752 \pm 468$ & $1623 \pm 445$ & $1978 \pm 433$ & 0,01 \\
\hline Glicídios (g) & $209,7 \pm 79,5$ & $192,1 \pm 72,8$ & $240,6 \pm 83,6$ & 0,05 \\
\hline Lipídios (g) & $74,0 \pm 19,9$ & $69,6 \pm 20,5$ & $81,7 \pm 16,7$ & 0,05 \\
\hline Proteína (g) & $62,0 \pm 19,4$ & $57,3 \pm 19,0$ & $70,5 \pm 17,6$ & 0,03 \\
\hline Ferro (mg) & $10,8 \pm 4,7$ & $9,9 \pm 3,7$ & $12,5 \pm 5,9$ & 0,08 \\
\hline Vitamina $C(\mathrm{mg})$ & $80,9 \pm 92,6$ & $59,0 \pm 57,7$ & $119,2 \pm 126,9$ & 0,04 \\
\hline
\end{tabular}


Características dietéticas (freqüência diária) durante o estudo. Campinas, 1997.

\begin{tabular}{|c|c|c|c|c|}
\hline Alimentos & Total & Experimental & Controle & $p$ \\
\hline 2a coleta & $(n=49)$ & $(n=32)$ & $(n=17)$ & \\
\hline Leite e derivados & $2,0 \pm 0,8$ & $1,2 \pm 0,8$ & $2,1 \pm 0,8$ & 0,63 \\
\hline Carnes & $2,5 \pm 0,9$ & $2,5 \pm 1,0$ & $2,4 \pm 0,7$ & 0,53 \\
\hline Energéticos & $3,6 \pm 1,2$ & $3,5 \pm 1,2$ & $3,6 \pm 1,0$ & 0,80 \\
\hline Verduras & $1,6 \pm 0,6$ & $1,6 \pm 0,6$ & $1,7 \pm 0,7$ & 0,83 \\
\hline Frutas & $1,1 \pm 0,5$ & $1,0 \pm 0,5$ & $1,2 \pm 0,6$ & 0,23 \\
\hline 3a coleta & $(n=47)$ & $(n=30)$ & $(n=17)$ & \\
\hline Leite e derivados & $1,9 \pm 0,7$ & $1,8 \pm 0,6$ & $2,2 \pm 0,7$ & 0,04 \\
\hline Carnes & $2,4 \pm 1,0$ & $2,5 \pm 1,0$ & $2,3 \pm 0,8$ & 0,61 \\
\hline Energéticos & $3,3 \pm 1,1$ & $3,3 \pm 1,1$ & $3,3 \pm 1,0$ & 0,87 \\
\hline Verduras & $1,6 \pm 0,6$ & $1,5 \pm 0,4$ & $1,8 \pm 0,8$ & 0,12 \\
\hline Frutas & $1,1 \pm 0,6$ & $1,0 \pm 0,6$ & $1,3 \pm 0,6$ & 0,19 \\
\hline 4a coleta & $(n=44)$ & $(n=29)$ & $(n=15)$ & \\
\hline Leite e derivados & $1,9 \pm 0,7$ & $1,7 \pm 0,7$ & $2,3 \pm 0,7$ & 0,02 \\
\hline Carnes & $2,5 \pm 1,0$ & $2,5 \pm 1,1$ & $2,4 \pm 0,9$ & 0,76 \\
\hline Energéticos & $3,3 \pm 1,0$ & $3,3 \pm 0,9$ & $3,5 \pm 1,2$ & 0,52 \\
\hline Verduras & $1,7 \pm 0,7$ & $1,7 \pm 0,7$ & $1,8 \pm 0,7$ & 0,56 \\
\hline Frutas & $1,0 \pm 0,6$ & $0,9 \pm 0,5$ & $1,3 \pm 0,7$ & 0,03 \\
\hline 5 a coleta & $(n=45)$ & $(n=29)$ & $(n=16)$ & \\
\hline Leite e derivados & $1,8 \pm 0,8$ & $1,7 \pm 0,7$ & $2,3 \pm 1,0$ & 0,04 \\
\hline Carnes & $2,4 \pm 0,8$ & $2,4 \pm 0,9$ & $2,4 \pm 0,7$ & 0,93 \\
\hline Energéticos & $3,3 \pm 0,8$ & $3,3 \pm 0,9$ & $3,4 \pm 0,7$ & 0,76 \\
\hline Verduras & $1,5 \pm 0,7$ & $1,4 \pm 0,7$ & $1,7 \pm 0,7$ & 0,20 \\
\hline Frutas & $1,0 \pm 0,5$ & $0,9 \pm 0,4$ & $1,2 \pm 0,6$ & 0,12 \\
\hline
\end{tabular}

te, analisou-se cada sintoma separadamente, não sendo constatada nenhuma diferença entre os grupos. O acompanhamento contínuo destes aspectos, durante todo o estudo, garantiu a segurança aos participantes, permitindo que o estudo continuasse até o final com o máximo de benefício e o mínimo de danos e riscos, conforme preconizam as normas éticas para pesquisa deste tipo (Brasil, 1996). Dois sujeitos do grupo experimental foram encaminhados para consulta médica por apresentarem algum sinal e sintoma que pudesse ser atribuído ao produto consumido, mas nenhum deles foi associado às cápsulas ingeridas.

\section{Variações hematimétricas ajustadas}

Para controlar a interferência da dieta nos níveis de ferro sérico, CLFF, ferritina, hematócrito, VCM e hemoglobina, as variáveis dietéticas diferentes entre os dois grupos foram consideradas no cálculo das médias ajustadas das variáveis hematimétricas a cada coleta. A Tabela 5 mostra os valores das médias não ajustada e ajustada para as variáveis em estudo apenas quando houve diferença estatisticamente significante, isto é, nas terceira, quarta e quinta coletas.

Verifica-se que os níveis de ferro sérico ficaram ainda maiores para o grupo experimental, em todas as etapas, sendo que, para o grupo controle, estes níveis diminuíram ainda mais. O CLFF, por outro lado, apresentou níveis um pouco menores no grupo experimental, em contraste com o grupo controle, que teve um pequeno aumento. Estes resultados indicam que o grupo experimental, em relação ao grupo controle, teve um bom aproveitamento do ferro durante todo o estudo. Quanto à ferritina, após ajuste das médias, os níveis mostraramse menores no grupo controle nas três últimas coletas e maiores no grupo experimental, após redução na terceira coleta. Em relação ao hematócrito, VCM e hemoglobina, não se observou diferença entre os dois grupos. 
Médias ajustadas das variações hematimétricas conforme a dieta. Campinas, 1998.

\begin{tabular}{|c|c|c|c|c|}
\hline Alimentos & Experimental & Controle & DP & $\mathrm{p}$ \\
\hline \multicolumn{5}{|l|}{ 3a coleta } \\
\hline \multicolumn{5}{|l|}{ Ferro Sérico $(g / d l)$} \\
\hline Média não ajustada (DP) & $23,7(36,9)$ & $1,6(34,0)$ & & 0,048 \\
\hline Ajustada para leite & 29,2 & $-3,3$ & 7,8 & 0,005 \\
\hline \multicolumn{5}{|l|}{ C.L.F.F. $(g / d l)$} \\
\hline Média não ajustada (DP) & $61,1(45,5)$ & $95,9(46,0)$ & & 0,002 \\
\hline Ajustada para leite & 58,2 & 101,9 & 10,5 & 0,005 \\
\hline \multicolumn{5}{|l|}{ Ferritina sérica (ng/dl) } \\
\hline Média não ajustada (DP) & $-6,0(8,9)$ & $-0,22(9,4)$ & & 0,004 \\
\hline Ajustada para leite & $-5,8$ & $-1,1$ & 2,1 & 0,124 \\
\hline \multicolumn{5}{|l|}{ 4a coleta } \\
\hline \multicolumn{5}{|l|}{$\operatorname{VCM}(f L)$} \\
\hline Média não ajustada (DP) & $-2,2(1,0)$ & $-3,1(1,6)$ & & 0,042 \\
\hline Ajustada para leite & $-2,3$ & $-2,8$ & 0,24 & 0,166 \\
\hline Ajustada para frutas & $-2,3$ & $-2,7$ & 0,30 & 0,32 \\
\hline Ajustada para todas & $-2,3$ & $-2,7$ & & 0,27 \\
\hline \multicolumn{5}{|l|}{ 5a coleta } \\
\hline \multicolumn{5}{|l|}{ Ferro Sérico (g/dl) } \\
\hline Média não ajustada (DP) & $35,2(39,2)$ & $10,1(39,7)$ & & 0,047 \\
\hline Ajustada para leite & 36,4 & 5,5 & 9,0 & 0,054 \\
\hline Ajustada para proteína & 36,9 & 6,6 & 0,32 & 0,022 \\
\hline Ajustada para vitamina C & 35,7 & 7,8 & 0,68 & 0,036 \\
\hline Ajustada para calorias & 35,6 & 7,9 & 0,14 & 0,043 \\
\hline Ajustada para todas & 40,8 & $-0,6$ & & 0,009 \\
\hline \multicolumn{5}{|l|}{ C.L.F.F. (g/dl) } \\
\hline Média não ajustada (DP) & $-6,1(46,3)$ & $34,3(63,9)$ & & 0,019 \\
\hline Ajustada para leite & $-8,7$ & 39,2 & 11,7 & 0,024 \\
\hline Ajustada para proteína & $-7,9$ & 36,2 & 0,45 & 0,019 \\
\hline Ajustada para vitamina C & $-7,4$ & 35,6 & 0,09 & 0,021 \\
\hline Ajustada para calorias & $-6,5$ & 34,8 & 0,02 & 0,03 \\
\hline Ajustada para todas & $-7,7$ & 38,1 & & 0,031 \\
\hline
\end{tabular}

Os dados obtidos neste estudo quanto ao ferro sérico e CLFF estão de acordo com a literatura. Segundo Rapaport (1990), o ferro sérico e o CLFF têm uma relação inversa entre si, fato também observado neste estudo. Quanto à ferritina, observou-se uma tendência à diminuição dos seus valores em algumas coletas, resultado semelhante ao encontrado por Wingard et al. (1995), que, ao estudar 46 pacientes anêmicos recebendo Eritropoietina Humana Recombinante (rHuEPO) e terapia oral de ferro por um período de seis meses, observaram uma diminuição dos níveis de ferritina em contraste com a manutenção dos níveis de hematócrito.
Zimmerman et al. (1995) compararam o uso de rHuEPO administrado via oral e subcutânea, em doses divididas e única, acrescidas de 80 mg de sulfato ferroso por 45 dias, em mulheres anêmicas pós-parto, e reportam redução nos níveis de ferritina no 14o dia de estudo, apesar do aumento da hemoglobina. Ainda em relação aos níveis de ferritina, Walter et al. (1993) avaliaram o impacto do programa chileno de suplementação de ferro da merenda escolar com biscoitos contendo fração celular desidratada após três anos de implantação e observaram diminuição dos valores de ferritina nos grupos caso e controle. Os autores observaram, 
ainda, aumento nas concentrações de hemoglobina, especialmente no grupo de meninas após a menarca, onde as necessidades de ferro estão aumentadas. O aumento da eritropoiese é também observado com a diminuição dos valores de ferritina, ou seja, pessoas com necessidades aumentadas de ferro (lactentes, crianças e mulheres) tendem a diminuir os valores de ferritina; entretanto, no nosso estudo, esta diminuição foi mais evidente no grupo controle, sendo que, no grupo experimental, os níveis de ferritina tenderam a se estabilizar ao final do período de estudo. Torres et al. (1995), ao estudarem o impacto do uso de leite fortificado com ferro e vitamina C sobre os níveis de hemoglobina de crianças menores de dois anos, encontraram aumento significativo de hemoglobina no grupo de crianças anêmicas, concluindo que o grupo de crianças anêmicas apresenta um poder de absorção de ferro muito maior do que o observado pelo grupo de crianças não anêmicas, o que corrobora os resultados deste estudo, realizado com pessoas não anêmicas, que apresentaram pequena alteração nos valores de hemoglobina, hematócrito e VCM.

De acordo com as hipóteses previamente formuladas, alterações nos níveis de hemoglobina não foram encontradas, pois todos os participantes do estudo apresentaram seus níveis normais no início do experimento. Entretanto, pode-se observar uma pequena tendência do grupo experimental em apresentar melhores resultados, não significantes estatisticamente, comparados ao controle. Observou-se, também, que os indivíduos, por apresentarem níveis normais de ferritina sérica no início do estudo, não aumentaram seus níveis durante o período do experimento, embora haja uma tendência favorável ao grupo experimental na última coleta, após ajuste das médias. O ferro sérico e o CLFF, por representarem uma resposta mais imediata de absorção de ferro, apresentaram diferença significativa entre os grupos, comprovando-se assim a hipótese formulada ao início do trabalho.

De modo geral, pode-se observar que o grupo experimental apresentou melhores resultados quanto aos parâmetros hematimétricos em relação ao controle. A comparação desses resultados com outros trabalhos da literatura torna-se difícil pela divergência das metodologias, da população, do tempo e do tipo de ferro utilizado nos estudos. Entretanto, os resultados encontrados indicam uma boa adequação do produto para o consumo humano e, principalmente, a possibilidade de uso na recuperação de níveis hematimétricos.
A diferença encontrada nos níveis hematimétricos entre os dois grupos persistiu para o ferro sérico e para a CLFF, nas terceira e quinta coletas.

Os dados da quinta e última coleta permitem ainda observar a interferência da dieta nos níveis de ferro sérico, cujo aumento pode estar relacionado com a melhoria na absorção do ferro não hematínico do grupo experimental pela presença de vitamina $C$ e proteína animal (Hurrell et al., 1988.), esta última também aumentada pela própria fração celular.

Todavia, quando se controlam os fatores dietéticos para os dois grupos, observa-se claramente o efeito do suplemento de ferro nos níveis de ferro sérico, muito maior no grupo experimental que no controle, diferenças de 40,8 $\mu \mathrm{g} / \mathrm{dl}$ e $-0,6 \mu \mathrm{g} / \mathrm{dl}$, respectivamente $(\mathrm{p}=0,009$ ).

Este resultado mostra que a medida do ferro sérico foi a mais sensível à suplementação oral de ferro para o período deste estudo e para esta população, cujo critério de ingresso na pesquisa eliminava qualquer possibilidade de anemia ferropriva.

\section{Conclusões}

O impacto da fração celular desidratada, rica em ferro hematínico, nos níveis hematimétricos de seres humanos foi determinado pelo estudo epidemiológico quase-experimental, sendo que o grupo suplementado com o ferro, apesar de apresentar níveis normais de estoque de ferro no início do estudo, obteve melhores resultados em comparação ao não suplementado, não havendo qualquer efeito colateral associado ao seu consumo. Observou-se, ainda, aumento significativo ( $\mathrm{p}=0,009)$ nos níveis de ferro sérico no grupo suplementado com a fração celular, indicando que o ferro desta fração foi absorvido e utilizado pela população do estudo no período de dois meses. Este estudo indica a possibilidade de uso deste produto no tratamento da anemia ferropriva. 


\section{Referências}

ASENJO, J. A.; AMAR, M.; CARTAGENA, N.; KING, J.; HICHE, E. \& STEKEL, A., 1985. Use of a bovine iron concentrate in the fortification of biscuits. Journal of Food Science, 50:795-799.

BATISTA-FILHO, M. \& FERREIRA, L. O. C. 1996. Prevenção e tratamento da anemia nutricional ferropriva: novos enfoques e perspectiva. Cadernos de Saúde Pública, 12:411-415.

BAUER, J. D.; TORO, G. \& ACKERMANN, P. G, 1962. Bray's Clinical Laboratory Methods. Saint Louis: Mosby Co.

FNS (Fundação Nacional de Saúde), 1996. Diretrizes e normas regulamentadoras de pesquisas envolvendo seres humanos. Informe Epidemiológico do SUS, 5:1-70.

CARPENTER, C. E. \& MAHONEY, A., 1992. Contributions of heme and nonheme iron to human nutrition. Critical Reviews in Food Science and Nutrition, 31:333-367.

CHEFTEL, J. C.; CUQ, J. L. \& LORIENT, D., 1989. Proteinas Alimentares. Zaragoza: Acribia.

DAVIDSOHN, I. \& HENRY, J. B., 1974. Clinical Diagnosis: By Laboratory Methods. Philadelphia: Saunders Company.

DOMENE, S. M. A., 1988. Utilização de sangue bovino para alimentação humana. Revista de Nutrição da PUCCAMP, 1:163-179.

FREIRE, W. B., 1998. La anemia por deficiencia de hierro: Estrategias de la OPS/OMS para combatirla. Salud Publica, 40:199-205.

GALLOWAY, R. \& McGUIRE, J., 1994. Determinants of compliance with iron suplementation: Supplies, side effects, or psychology? Social Science and Medicine, 39:381-390.

GORINA, A. B. \& JIMENEZ, M. S., 1974. La Clínica y el Laboratorio - Interpretación de Análisis y Pruebas Funcionales. Barcelona: Marin.

HALLBERG, L.; BENGTSSON, C.; LAPIDUS, L.; LINDSTEDT, G.; LUNDBERG, P. A. \& HULTEN, L., 1993. Screening for iron deficiency: An analysis based on bone-marrow examinations and serum ferritin determinations in a population sample of women. British Journal of Haematology, 85:787-798.

HENRY, J. B., 1995. Diagnósticos Clínicos e Tratamentos por Métodos Laboratoriais. São Paulo: Malone.

HURRELL, R. F.; LYNCH, S. R.; TRINIDAD, T. P.; DASSENKO, S. A. \& COOK, J. D., 1988. Iron absorption in humans: Bovine serum albumin compared with beef muscle and egg white. The American Journal of Clinical Nutrition, 47:102-107.

KLEINBAUM, D. G., KUPPER, L. L. \& MORGENSTERN, H., 1982. Epidemiologic Research: Principles and Quantitative Methods. New York: Van Nostrand.

KREBS-SMITHS, S. M. \& CLARK, L. D., 1989. Validation of a nutrition adequacy score for use with women and children. Journal of the American Dietetic Association, 89:775-780.

LEE, Y. Z.; AISHIMA, T.; NAKAI, S. \& SIM, J. S., 1987. Optimization for selective fractionation of bovine blood plasma proteins using polyethylene glycol. Journal Agriculture Food Chemical, 35:958-962.

NAOUM, P. C., 1987. Diagnóstico das Hemoglobinopatias. São Paulo: Savier.
NOGUEIRA, N. N.; COLLI, C. \& COZZOLINO, S. M. F., 1992. Controle da anemia ferropriva em pré-escolares por meio da fortificação de alimento concentrado de hemoglobina bovina (estudo preliminar). Cadernos de Saúde Pública, 8:459-465.

RAPAPORT, S. I., 1990. Introdução à Hematologia. São Paulo: Roca.

SIMMONS, W. K.; COOK, J. D.; BINGHAM, K. C.; THOMAS, M.; JACKSON, J.; JACKSON, M.; AHLUWALIA, N.; KAHN, S. G. \& PATTERSON, A. W., 1993. Evaluation of a gastric delivery system for iron supplementation in pregnancy. American Journal of Clinical Nutrition, 58:622-626.

SIMÕES, M. C. C., 1998. Desenvolvimento de um Suplemento Nutricional Rico em Ferro Hematínico. Dissertação de Mestrado, Campinas: Faculdade de Engenharia de Alimentos, Universidade Estadual de Campinas.

SPSS, 1992. Advanced Statistics. Release 5. Chicago: SPSS Incorporation.

STEKEL, A.; MONCKEBERG, F. \& BEYDA, V., 1986. Prevención de la Deficiencia de Hierro: La Experiencia de Chile. Santiago: International Life Sciences Institute Nutrition Foundation.

TABACNIKS, M. H. \& MOURA, E. C., 1992. AVANU Avaliação Nutricional. Campinas: Pontifícia Universidade Católica de Campinas.

TIETZ, N. W., 1987. Fundamentals of Clinical Chemistry. Philadelphia: Saunders Company.

TORRES, M. A. A.; ATO, K.; LOBO, N. F. \& QUEIROZ, S. S., 1995. Efeito do uso de leite fortificado com ferro e vitamina C sobre os níveis de hemoglobina e condição nutricional de crianças menores de dois anos. Revista de Saúde Pública, 29:301-307.

VASCONCELOS, F. A. G., 1995. Avaliação Nutricional de Coletividade. Florianópolis: Universidade Federal de Santa Catarina.

WALKER, A. R., 1998. The remedying of iron deficiency: What priority should it have? British Journal of Nutrition, 79:227-235.

WALTER, T.; HERTRAMPF, E.; PIZARRO, F.; OLIVARES, M.; LLAGUNO, S.; LETELIER, A.; VEGA, V. \& STEKEL, A., 1993. Effect of bovine-hemoglobinfortified cookies on iron status of schoolchildren: A nationwide program in Chile. American Journal of Clinical Nutrition, 57:190-194.

WILLETT, W., 1998. Nutritional Epidemiology. New York: Oxford Press.

WILLIAMS, H. L.; JOHNSON, D. J. \& HAUT, M. J., 1977. Simultaneous spectrophotometry of Fe2+ and $\mathrm{Cu} 2+$ in serum denatured with guanidine hydrochloride. Clinical Chemistry, 23:237-240.

WINGARD, R. L.; PARKER, R. A.; ISMAIL, N. \& HAKIM, R. M., 1995. Efficacy of oral iron therapy in patients receiving recombinant human erythropoietin. American Journal of Kidney Diseases, 25: 433-439.

ZIMMERMANN, R.; BREYMANN, C.; RICHTER, C.; HUCH, R. \& HUCH, A., 1995. rhEPO treatment of postpartum anemia. Journal of Perinatal Medicine, 23:111-117. 